\title{
O desenvolvimento (in)sustentável do agronegócio canavieiro
}

\author{
(Un)sustainable development of the sugarcane agribusiness
}

Polyana Felipe Ferreira da Costa ${ }^{1}$

Marcelo Saturnino da Silva ${ }^{2}$

Solange Laurentino dos Santos ${ }^{3}$

${ }^{1}$ Programa de PósGraduação em Saúde Coletiva, Universidade Federal de Pernambuco. Av. Prof. Moraes Rego s/n, Cidade Universitária. 50.670-901 Recife PE Brasil.polyanafelipe@yahoo. com.br

${ }^{2}$ Departamento de Educação da Universidade Estadual da Paraíba.

${ }^{3}$ Departamento de Medicina Social,

Universidade Federal de

Pernambuco.
Abstract In the past few years the sugarcane agribusiness has been experiencing considerable expansion, being presented as a symbol of progress and the most developed industry in the country. In this article, we investigate the myths surrounding this sector of the Brazilian economy, revealing the environmental injustices and suffering experienced by northeastern workers who relocate every year to work in the sugarcane regions. We conducted a methodological study of the specialized literature on the sugarcane agribusiness and its interface with the migration of northeastern workers and the labor conditions and relations to which these individuals are subjected. We also use data from our own research developed in the micro regions of Pajeu in the State of Pernambuco and Princesa Isabel in the State of Paraiba. The data reveal the human and environmental unsustainability of the sugarcane agribusiness, demystifying the sweetness of sugarcane and purity of ethanol produced in Brazil, since this production is strongly influenced by perverse conditions, the social consequences of which have been the destruction of the environment and the flora and fauna, the exploitation of labor and workers in this process marked by illness and, in many cases, death.

Key words Development, Migration, Agribusiness, Work, Illness
Resumo Nos últimos anos o agronegócio canavieiro vem passando por um surto de expansão, sendo apresentado como emblema do progresso e do que há de mais desenvolvido no país. No presente artigo, busca-se questionar os mitos construidos em torno desse setor da economia brasileira, desvelando as injustiças ambientais e o sofrimento vivenciado por trabalhadores nordestinos que anualmente se deslocam para oferecer sua força de trabalho nas regiões canavieiras. Metodologicamente, lançamos mãos da literatura especializada sobre agronegócio canavieiro em sua interface com a migração dos trabalhadores nordestinos $e$ com as condições e relações de trabalho nas quais esses sujeitos estão inseridos. Utilizamos ainda dados de nossas próprias pesquisas desenvolvidas, na microrregião do Pajeú, Estado de Pernambuco e de Princesa Isabel - Paraíba. Os dados sinalizam para a (in) sustentabilidade ambiental e humana do agronegócio canavieiro, desmistificando, dessa forma, a doçura da cana e a pureza do etanol produzido no Brasil, uma vez que tal produção é fortemente marcada por condições perversas, cujas consequências sociais tem sido a depredação do meio ambiente, a destruição da flora e da fauna, a exploração do trabalho e dos trabalhadores marcados neste processo com o signo do adoecimento $e$ não raramente da morte.

Palavras-chave Desenvolvimento, Migração, Agronegócio, Trabalho, Adoecimento 


\section{Introdução}

Em artigo publicado recentemente no jornal "Folha de São Paulo", Dana ${ }^{1}$, professor de Economia na Escola de Economia de São Paulo (FGV), mostra a importância da agricultura brasileira, em números. Embora o título do referido artigo faça referência à agricultura brasileira, o foco é no agronegócio, enunciado como setor fundamental na economia do país, responsável, em 2013, por $23 \%$ do Produto Interno Bruto (PIB) nacional; por 32\% dos empregos; e pelo superávit positivo da balança comercial. O autor encerra seu artigo apresentando o agronegócio como "exemplo de eficiência e dinamismo econômico (...), setor símbolo de excelência empresarial e um dos pilares da maior economia da América Latina".

O discurso competente de Dana ${ }^{1}$, no entanto, não faz referência aos custos sociais e ambientais do agronegócio. Justiça seja feita ao autor: há no corpo do texto a indicação de que o mesmo agronegócio que foi responsável por 32\% dos empregos, em 2013 , e por $41,3 \%$ das exportações nacionais, também foi responsável por $34,8 \%$ das emissões de gás carbônico $\left(\mathrm{CO}_{2}\right)$ no país, no entanto desta afirmativa não se tira qualquer consequência.

Claro que qualquer leitor entende o que significa "ser responsável por 32\% dos empregos", ou pelo "saldo positivo da balança comercial", o que não se entende de forma automática é quais as consequências da emissão de gás carbônico para o meio ambiente e, consequentemente, para a saúde de plantas, animais e seres humanos.

No documentário "Nuvens de Veneno"2, o professor da Universidade Federal do Rio de Janeiro (UFRJ), Roberto Novaes, apresenta outra dimensão do agronegócio canavieiro, levando o expectador a questionar que desenvolvimento e que excelência empresarial é esta que, em nome do crescimento econômico, explora o trabalhador, desmata, polui e envenena o meio ambiente e a vida, inclusive a vida humana.

Essa ideia de desenvolvimento como expressão de crescimento econômico, como já denunciada por Celso Furtado ${ }^{3}$, não passa de um mito, entendido no sentido de ideia compartilhada e amplamente aceita, que se expressa - ao mesmo tempo em que é renovado/atualizado -, em comportamentos, costumes e hábitos ${ }^{4}$. Conforme Cavalcanti ${ }^{4}$, a ideia de "mito do desenvolvimento", em Celso Furtado, está relacionada ao fato, facilmente averiguável, de que tal modelo "destrói e degrada em larga escala o meio ambiente, além de criar a ilusão de que, crescendo a economia, tem-se desenvolvimento".
Não obstante a denúncia do economista paraibano tenha sido feita a mais de três décadas, o mito do desenvolvimento continua presente no ideário e na prática de empresários e formuladores das políticas públicas no Brasil. Assim é que nos últimos anos tem-se assistido, no território brasileiro, ao (re)florescimento de grandes empreendimentos empresariais, não raramente capitaneados por incentivos estatais, que surgem e ressurgem graças à aposta de setores políticos e econômicos de que tais empreendimentos representam a solução para o desenvolvimento do país. Como expressão dessa tendência pode-se citar, por um lado, o Plano de Aceleração do Crescimento (PAC) e, por outro, o fortalecimento e atual processo de expansão do agronegócio pensado como exemplo de sucesso da agricultura brasileira.

Tomando como referência o caso da indústria canavieira, busca-se, no presente artigo, refletir sobre as consequências ambientais, sociais e humanas dos atuais processos de desenvolvimento, presentes no território brasileiro, a partir da perspectiva dos vencidos. Reconhecendo o fetichismo das mercadorias (sejam estas o etanol ou o açúcar), buscar-se-á reestabelecer e tornar visíveis as relações sociais das quais tais mercadorias são expressões, minando, por este mesmo processo, seu poder de encantamento.

\section{Métodos}

Os dados são resultados de pesquisa bibliográfica e documental, entendida como a que "explica um problema a partir de referenciais teóricos publicados em documentos" ${ }^{\text {" }}$. Este levantamento bibliográfico foi realizado na base de dados "Scielo", onde foram escolhidos os artigos que tivessem como foco o agronegócio canavieiro em interface com a migração, trabalho e adoecimento.

Foi feito também levantamento bibliográfico em dissertações, teses, livros, e publicações de jornais. Foram utilizados, ainda, dados secundários da Companhia Nacional de Abastecimento (CONAB) e também do Instituto Brasileiro de Geografia e Estatísticas (IBGE), além de dados de pesquisas desenvolvidas pelos autores, na microrregião do Pajeú, Estado de Pernambuco e de Princesa Isabel, Paraíba.

O material encontrado foi catalogado e analisado a partir das seguintes categorias: (1) situação atual do setor; (2) consequências ambientais, sociais e humanas, com destaque para a questão da saúde dos trabalhadores e, especificamente, dos trabalhadores migrantes. 


\section{Resultados e discussão}

\section{$O$ atual processo de expansão do setor canavieiro}

O agronegócio canavieiro no Brasil vem passando, nas duas últimas décadas, por um novo surto de expansão, sendo apresentado como emblema do progresso e do que há de mais desenvolvido no país. Tal processo está atrelado à busca por novas fontes de energias (limpas e renováveis), que possam substituir o petróleo; bem como ao desenvolvimento de motores flex-fuel. Nesse contexto a cana-de-açúcar aparece como a solução perfeita tanto para a crise energética quanto para os desafios ambientais expressos no aquecimento global ${ }^{6}$.

Segundo dados da CONAB (2013), a previsão para o ano de 2014 é que a área plantada com cana-de-açúcar tenha um acréscimo de aproximadamente 3,7\% em relação ao anterior, sendo que a maior parte da produção canavieira (56\%) está localizada no Estado de São Paulo (Gráfico 1).

Pesquisadores e movimentos sociais têm chamado a atenção para as possíveis relações entre tal processo de expansão das lavouras canavieiras e a segurança alimentar, uma vez que uma significativa parcela do espaço anteriormente dedicado a várias culturas agrícolas tem sido atualmente ocupado, exclusivamente, pela canade-açúcar. Nesse âmbito o debate pode ser organizado em torno de duas linhas, sendo a primeira delas representada pelos que advogam que a expansão da cultura canavieira caminha vis-à-vis com o retraimento de outras culturas bem como

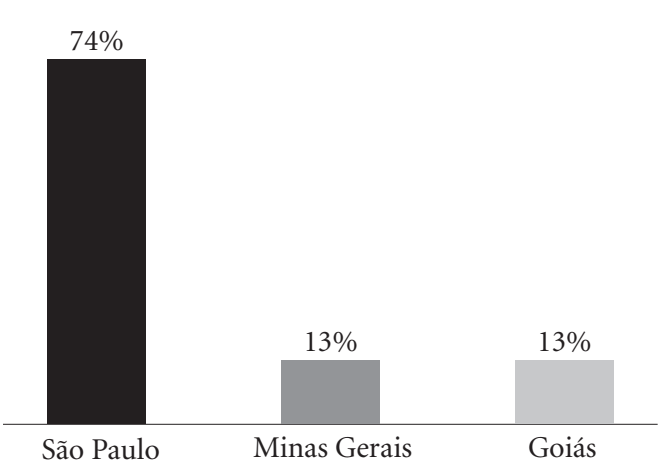

Gráfico 1. Cana-de-açúcar, principais estados produtores, área plantada (2012/2013) \%

Fonte: Companhia Nacional de Abastecimento - CONAB (2013). da pecuária leiteira levando a uma alta no preço dos alimentos e ao agravamento da insegurança alimentar; e, a segunda, pelos que defendem a ideia de que não existe uma relação direta entre expansão da área plantada com cana-de-açúcar e o agravamento da crise alimentar.

Expressão da primeira tendência pode ser localizada já no pensamento de Celso Furtado ${ }^{3}$, que em 1959 respondendo à indagação do presidente Juscelino advogou que a ação do governo federal no Nordeste "deveria privilegiar a produção de alimentos, tanto no semiárido como nas terras úmidas litorâneas, hoje monopolizadas pela canade-açúcar" . Contemporaneamente podemos citar como autores que defendem tal tendência o sociólogo suíço e relator especial da ONU sobre o direito a alimentação, Jean Ziegler ${ }^{8}$, que em entrevista ao jornal Folha de São Paulo assim se pronunciou:

Durante um tempo o açúcar sofreu um declinio, e a agricultura se desenvolveu. Agora esse monstro está de volta, devorando a terra da agricultura. O açúcar voltou a ser santificado, como na época da colônia, quando a oligarquia enriqueceu e a música, a cultura, tudo era pago pelo açúcar\$.

A segunda tendência que marca o debate expansão da cana-de-açúcar versus segurança alimentar é representada por um grupo de autores que defende a ideia de que o processo de expansão das usinas canavieiras não compromete a produção de outros alimentos nem a criação de gado, já que a maior utilização de tecnologias e insumos permite uma maior intensificação da produção, favorecendo uma maior produtividade numa menor extensão de terras cultivadas. Assim é que o geógrafo alemão Gerd Kohlhepp ${ }^{9}$, amparando-se em dados do Instituto de Economia Aplicada (IPEA), e tomando como exemplo o Estado de São Paulo, advoga que a diminuição da área dedicada à cultura de feijão no período de 1990-2008 não implicou em menor produção, ao contrário, mesmo sendo cultivado numa área menor, devido à duplicação da produtividade, a produção desse grão teria aumentado $16 \%$ no mesmo período ${ }^{9}$. Ideia semelhante é defendida também por Ricardo Abramovay ${ }^{10}$, para quem o impacto do agronegócio sobre a produção de alimentos é relativamente reduzido.

Tomando como referências dados do Instituto Brasileiro de Geografia e Estatística (IBGE) relativos ao município de Novo Horizonte, interior do Estado de São Paulo, podemos observar que de fato há um processo de retraimento da área dedicada às outras lavouras (a exemplo do feijão e do milho), bem como do efetivo do rebanho bovino (Gráficos 2 e 3) vis-à-vis uma expansão 
da área dedicada ao cultivo de cana-de-açúcar (Gráfico 4). Com relação ao aumento de produtividade não há evidências, para o município em questão, uma vez que o retraimento da área plantada implicou igualmente em diminuição da produção dos dois grãos aqui considerados (feijão e milho) (Gráfico 5).

É importante enfatizar que os dados acima apresentados fazem referência a um espaço concreto. Dessa forma, as conclusões tiradas a partir da leitura dos mesmos não podem ser generalizadas. No entanto, permitem questionar a tese segundo a qual a expansão da cana-de-açúcar não tem um impacto negativo sobre a produção de alimentos. De fato, tal impacto parece existir, mensurar sua intensidade requer, no entanto, um maior esforço empírico por parte dos pesquisadores.

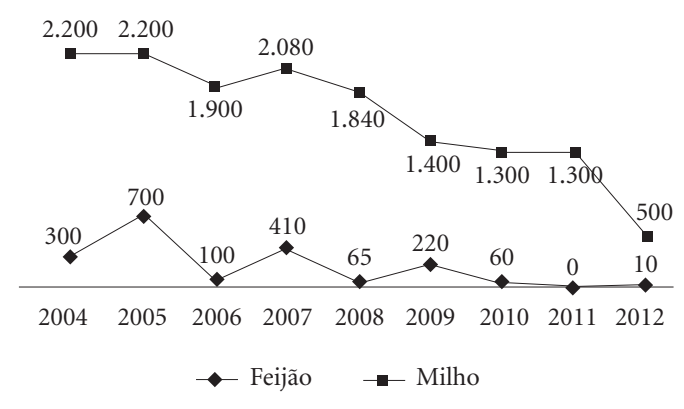

Gráfico 2. Evolução da Produção agrícola (área plantada, Novo Horizonte - SP).

Fonte dos dados: Instituto Brasileiro de Geografia e Estatísticas (IBGE)

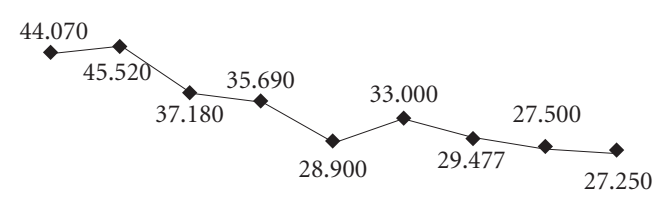

$2004 \quad 2005 \quad 2006 \quad 2007 \quad 2008 \quad 2009 \quad 2010 \quad 20112012$

Gráfico 3. Evolução da Pecuária Bovina (por cabeça, Novo Horizonte/ SP).

Fonte dos dados: Instituto Brasileiro de Geografia e Estatísticas (IBGE)
Mesmo considerando a possibilidade da intensificação da produção agrícola, é necessário não subestimar o fato de que produção intensiva, no atual modelo produtivo, implica mais utilização de insumos em termos de fertilizantes, adubos químicos e agrotóxicos o que implica em maiores níveis de degradação ambiental com efeitos nefastos sobre a saúde da população e do planeta $^{11}$.

Sobre os efeitos ambientais da produção canavieira, é importante considerar também que embora a produção do etanol a partir da canade-açúcar tenha contribuindo para a redução de gás carbônico, diminuição do efeito estufa etc., por outro lado, tem sido altamente poluente nas regiões onde se implantou afetando negativamente a biodiversidade, contaminando rios,

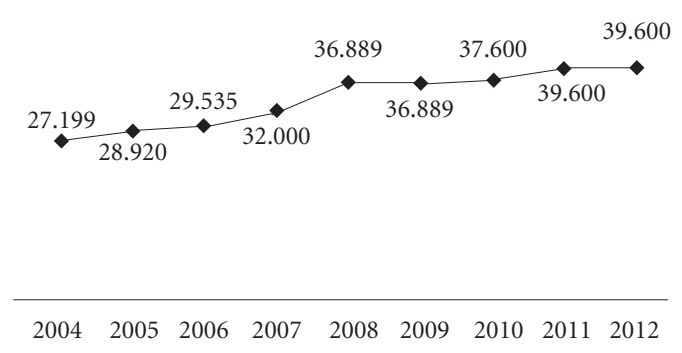

Gráfico 4. Evolução da Produção de cana-de-açúcar (área plantada, Novo Horizonte - SP).

Fonte dos dados: Instituto Brasileiro de Geografia e Estatísticas (IBGE)

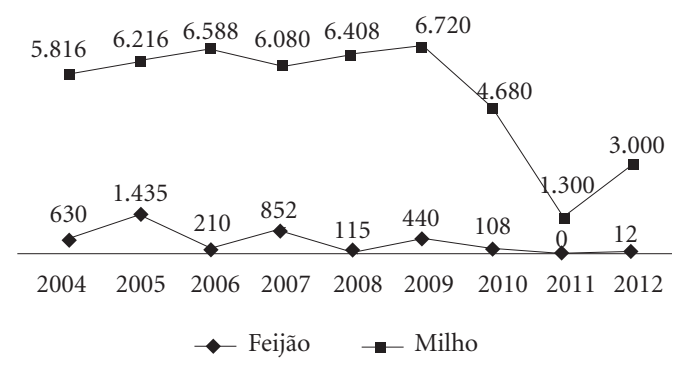

Gráfico 5. Evolução da Produção Agrícola (quantidade produzida, por tonelada, Novo Horizonte $-\mathrm{SP})$.

Fonte dos dados: Instituto Brasileiro de Geografia e Estatísticas (IBGE) 
lençóis freáticos, solo; provocando, assim, desequilíbrio agroecológico ${ }^{12}$.

Mesmo considerando o processo de mecanização da colheita de cana-de-açúcar no Estado de São Paulo, é importante não perder de vista o fato de que tal processo ainda não atinge $100 \%$ da área plantada, razão pela qual ainda persiste a prática das queimadas. Esta prática, conforme documenta a literatura especializada, polui o ar e o solo, destrói os microrganismos, além de implicar no extermínio da fauna e da flora ${ }^{12}$. Além disso, a emissão de poluentes acaba interferindo negativamente sobre a saúde da população.

Mas é em relação aos aspectos humanos que a produção do etanol da cana-de-açúcar, revela toda a sua "sujeira". Com efeito, a expansão da cana de açúcar tem contribuído para a intensificação dos fluxos migratórios, especificamente de indivíduos provenientes dos Estados Nordestinos e do Vale de Jequitinhonha (MG) que anualmente se dirigem aos canaviais do Estado de São Paulo, onde vão oferecer sua força de trabalho por alguns meses do ano.

Embora a migração de nordestinos para a região sudeste do país, especificamente para os Estados de Rio de Janeiro e São Paulo, ocorra desde os anos de 1950, a partir da segunda metade da década de 1990, com a crise dos empregos urbanos - influenciada pelo fenômeno denominado de reestruturação produtiva - e, simultaneamente, com o novo ciclo de expansão da indústria canavieira, houve um redirecionamento desses fluxos migratórios que passaram a ser caracterizados pela sazonalidade e a ter como destino não mais os grandes centros urbanos, mas as regiões produtoras de cana-de-açúcar, a exemplo da região de São José do Rio Preto, no Estado de São Paulo.

Inseridos em um contexto marcado pela vulnerabilidade: dificuldade de acesso a terra, fatores climáticos, poucas opções de emprego não agrícola etc.; muitos indivíduos oriundos de famílias camponesas, tendo como centralidade seus espaços de moradia, tendem a se conectar a outros lugares, mobilizando-se em busca de acesso a trabalho e renda visando à satisfação de suas necessidades e, em última instância, a reprodução de seu grupo familiar. Na microrregião do Pajeú, Sertão de Pernambuco e partes da microrregião da Serra da Teixeira, no Estado da Paraíba, grande parcela da população economicamente ativa vem lançando mão da migração sazonal, tendo como destino, sobretudo, a microrregião de São José do Rio Preto, interior do Estado de São Paulo, onde vão oferecer sua força de trabalho no plantio e na colheita de cana-de-açúcar.
Dados de pesquisas realizadas por Silva ${ }^{13}$; Costa e Silva ${ }^{14}$ e por outros pesquisadores ${ }^{15}$, apontam que a maioria dos que migram são jovens, com pouca escolaridade, residentes nas áreas oficialmente tidas como rurais (sítios e povoados) dos pequenos municípios dos Estados nordestinos e também da região do Vale do Jequitinhonha em Minas Gerais.

Tais trabalhadores são recrutados nos pequenos municípios nordestinos, geralmente nos primeiros meses do ano. O processo de recrutamento é realizado mediante as redes de sociabilidade locais, expediente este que visa garantir um trabalhador padrão, isto é, indivíduos dóceis e úteis, tanto mais úteis quanto mais dóceis ${ }^{16}$.

O trabalho na colheita de cana-de-açúcar tem sido denunciado por vários pesquisadores ${ }^{17-19}$, como degradante, caracterizado pelo alto grau de exploração da força de trabalho, haja vista os atuais níveis de produtividade exigidos pelas empresas, bem como pela exposição dos trabalhadores aos efeitos do calor intensivo e a agentes químicos "oriundos dos hidrocarbonetos aromáticos e outros compostos de carbono reativos à queima incompleta das palhas de cana-de-açúcar" ${ }^{19}$, os quais podem ocasionar vários danos à saúde ${ }^{20}$.

Wanderley ${ }^{21}$ chama a atenção para o fato de que o modelo de modernização da agricultura brasileira, sob o comando da terra, não modernizou "as condições de vida e de trabalho dos assalariados". A introdução de insumos e tecnologias "poupadores do trabalho vivo" levou a uma diminuição, mas não extinguiu a necessidade de trabalho manual. Na produção da cana-de-açúcar, esta necessidade é suprida "por migrantes de todas as origens e pela força de trabalho instalada no interior da agricultura de base familiar"21, os quais, visando garantir a reprodução de seus grupos familiares se "submetem" às experiências mais degradantes de trabalho humano, condições estas consideradas como análogas ao trabalho escravo.

Resultado desse processo de intensificação e precarização do trabalho no cotidiano das empresas do setor canavieiro e que tem como fundamento a busca pela extração de mais sobretrabalho, são as inúmeras mortes dos trabalhadores em decorrência do excesso do trabalho, conforme atestado por Silva ${ }^{22}$.

Rocha $^{23}$ afirma que "o trabalho manual na colheita de cana-de-açúcar representa riscos à saúde dos trabalhadores, devido ao calor intenso, constante radiação solar, poeira proveniente do solo, fuligem da cana queimada e a presença de animais peçonhentos". Há também risco acen- 
tuado de acidentes de trabalho em decorrência do manuseio do facão.

$\mathrm{O}$ excesso de trabalho, associado às longas jornadas sob o sol e reposição inadequada de nutrientes e sais minerais, resulta em distúrbios hidroeletrolíticos cujos episódios de gravidade crescente se manifestam de câimbra a morte por parada cardíaca. As câimbras são fortes e frequentes, seguidas de tontura, dor de cabeça, vômito e convulsões, os trabalhadores denominam esta condição/situação de "Birola"24. Outros desgastes físicos são relatados por Alessi e Scopinho ${ }^{25}$.

Fundamentando-se em dados do Instituto de Economia Agrícola (IEA), ligado à Secretaria de Agricultura e Abastecimento do Governo de São Paulo, Pedro Ramos advoga que, não obstante os maiores níveis de produtividade alcançados pelas usinas canavieiras, a remuneração dos trabalhadores no corte da cana queimada, "teve queda real aproximada de 30\% de meados da década de 1980 para atualidade"26, ou seja, o aumento de produtividade não implicou em melhores rendas e, consequentemente, em mais qualidade de vida dos trabalhadores, ao contrário, o que houve foi uma intensificação do processo de produção de mais-valia, com os trabalhadores produzindo um volume maior de riqueza e, paradoxalmente, se apropriando de parcela cada vez menor de seu trabalho.

Uma forma de favorecer o cumprimento, e mesmo a ultrapassagem das metas de produtividade, por parte dos trabalhadores foi mediante o atrelamento do salário à produtividade, expediente que tem levado os trabalhadores a um processo de autoexploração. Essa forma específica de remuneração, ao mesmo tempo em que incentiva a intensificação do trabalho e a extensão da jornada de trabalho, funciona também como um engenhoso método de introjeção da disciplina e do autocontrole por parte do trabalhador ${ }^{27}$.

Outro fenômeno que vem acontecendo no setor canavieiro é a redução do número de trabalhadores que são recrutados para trabalharem nas usinas de cana-de-açúcar do Estado de São Paulo, decorrente do avanço da mecanização para atender ao Protocolo Ambiental assinado entre o Governo do Estado de São Paulo e a UNICA em 2007. Tal acordo prevê, dentre outras coisas, a eliminação da queimada da palha nos canaviais até 2014 (ao invés de 2021) para terrenos com declividade até $12 \%$ e até o ano de 2017 (ao invés de 2031) para aqueles com declividade superior ${ }^{28}$.

Vários autores ${ }^{19,29-31}$ têm realçado que o atual processo de mecanização vivenciado pelo setor canavieiro deve ser entendido à luz dos seguintes fatores: (I) a intensificação da tecnologia, que implicou em máquinas mais potentes e com preços e custos de manutenção mais baixos; (II) o discurso ambiental, que desvelando o mito do etanol enquanto energia limpa contribuiu para atrelar a expansão das exportações desse biocombustível à demonstração de que a produção do mesmo não agride o meio ambiente nem degrada as condições de trabalho; e por fim, (III) o aumento nos custos da colheita manual visto que nos últimos anos tem crescido o numero de processos trabalhistas movidos pelos trabalhadores-migrantes contra as empresas canavieiras visando, sobretudo, à cobrança de direitos supostamente desrespeitados durante o tempo da safra.

Quando se observa o discurso em torno da mecanização da colheita de cana-de-açúcar, percebe-se a tentativa de construção de um mito relacionando tal processo a maior qualidade nas condições de trabalho ${ }^{29}$. Rocha ${ }^{23}$, no entanto, em sua tese de doutorado, apresenta outra visão em relação à colheita mecanizada e seus reflexos na saúde dos trabalhadores. Com efeito, se por um lado, ao passar "a maior parte do tempo dentro das cabines das máquinas, os operadores estão menos susceptíveis aos riscos ocupacionais decorrente da exposição à radiação solar, calor, poeira, fuligem e resíduos agrotóxicos" ficando, assim, menos susceptível "às doenças respiratórias e cutâneas relacionadas ao corte manual da cana"23, por outro lado,

O conjunto de movimentos realizados no comando das colhedeiras e o fato de permanecerem sentados durante toda a jornada de trabalho, não realizarem pausas regulares e estarem impossibilitados de realizar atividades de alongamentos ou extensão dos membros e tronco com frequência devido às reduzidas medidas das cabines das colhedeiras expõem os operadores ao risco de serem acometidos principalmente por lombalgias e cervicalgias.

A referida autora chama a atenção ainda para outros riscos aos quais os operadores das colhedeiras mecânicas estariam susceptíveis, dentre eles: alterações no ritmo cardíaco, fadiga mental, stress, sofrimento psíquico, envelhecimento precoce, distúrbios no padrão do sono, problemas cardiovasculares e gastrintestinais ${ }^{23}$.

As citações dos autores acima, portanto, expressam o duplo processo pelo qual passa hoje o trabalho nas empresas do setor canavieiro. Por um lado, há em curso um processo de mecanização com a consequente diminuição do trabalho vivo, o que representa uma fonte de sofrimento para os "desempregados", que se vêm "obrigados" 
a buscarem inserir-se em outros setores econômicos e a aceitarem ocupações com os mesmos ou maiores riscos ocupacionais e onde o trabalho é tão ou mais intenso do que aquele na lavoura canavieira. Por outro lado, há também um processo de intensificação do trabalho vivo, seja este realizado na colheita mecânica, com o auxílio das máquinas, seja na colheita manual, visto que as atuais médias de produtividade exigida pelo setor encontram-se muito aquém do humanamente decente, mas que, não obstante, os trabalhadores e trabalhadores devem se submeter, movidos inclusive pela esperança de que, ao assim se comportarem, seus nomes não venham a ser incluídos nas listas das próximas demissões.

A intensificação da mecanização da colheita de cana-de-açúcar coloca ainda a questão sobre o destino dos trabalhadores-migrantes. Utilizando dados do Ministério do Trabalho e Emprego, os autores $^{29}$ realçam que no ano de 2007 a indústria canavieira contratou, apenas no Estado de São Paulo, 178.510 trabalhadores para atuarem na colheita manual de cana-de-açúcar, dois anos depois, em 2009, foram 154.274 trabalhadores contratados, ou seja, em apenas dois anos, foram dispensados, do corte manual, 24.236 trabalhadores, uma queda de $13,6 \%$ no período então considerado.

Os referidos autores apontam que grande parte desses trabalhadores, excluídos das usinas canavieiras, tem ingressado em outros setores produtivos, especificamente, na construção civil, setor que atualmente passa também por um momento de expansão, também capitaneado pelo Estado, sobretudo através do Programa de Aceleração do Crescimento (PAC), que vem promovendo a execução de grandes obras de infraestrutura social, urbana, logística e energética no país ${ }^{32}$ - a exemplo da transposição do Rio São Francisco e da construção da Transnordestina e do Porto de SUAPE (Estado de Pernambuco), e ainda do Programa Habitacional "Minha casa, minha Vida" etc.

Rocha e Hashizume ${ }^{33}$ em reportagem divulgada pelo site da ONG Repórter Brasil, enfatizam a migração de cortadores de cana-de-açúcar para o ramo da construção civil, como consequência do processo de mecanização da colheita de cana. Os referidos repórteres chamam a atenção para o caso dos trabalhadores-migrantes, os quais "acabam se sujeitando a trabalhar em situação pior do que a dos próprios cortadores"33.

Conforme enfatizado por Menezes et al. ${ }^{29}$, esta migração do trabalhador canavieiro para o setor da construção civil não representa melho- rias nas condições de trabalho e vida desses sujeitos, isto porque as condições e relações de trabalho no setor da construção civil seriam tão ou mais degradantes que as apresentadas pelo trabalho na colheita de cana, haja vista que a construção civil é marcada pela informalidade, cargas intensas de trabalho e riscos de acidentes etc. ${ }^{29,33}$.

No ano de 2010, a Odebrechet, empresa responsável pelas obras da Ferrovia Transnordestina, divulgava informativo lamentando acidente ocorrido no trecho da referida ferrovia, localizado na cidade de Paulistana (PI), o qual teria resultado na morte de dois (2) e no ferimento de doze (12) trabalhadores. Em Junho de 2011, a mesma construtora (Odebrechet) foi autuada pelo Ministério Público do Trabalho do Estado de Pernambuco, em virtude de várias irregularidades, relativas ao meio ambiente e trabalho, detectadas durante força-tarefa nacional realizada pelo Ministério Público do Trabalho, no período em destaque.

Como se percebe, o fim da queima da cana-de-açúcar e a mecanização da colheita desta cultura não implicaram em melhores condições de trabalho e saúde para os trabalhadores. O que houve, conforme os dados sinalizam, foi um deslocamento do problema para outros setores econômicos do país.

Nesse sentido, o crescimento econômico que aconteceu no setor canavieiro não pode ser entendido como "desenvolvimento". O desenvolvimento para Armatya $\mathrm{Sen}^{34}$ é definido como o processo de ampliação da capacidade de os indivíduos terem opções, fazerem escolhas. Ele relativiza os fatores materiais e os indicadores econômicos e insiste na ampliação do horizonte social e cultural da vida das pessoas ${ }^{34}$.

\section{Afinal, que desenvolvimento é este?}

Intencionou-se, no presente artigo, dar visibilidade ao desenvolvimento insustentável do agronegócio canavieiro desmistificando, dessa forma, a doçura da cana e a pureza do etanol produzido no Brasil, em condições perversas que, como vimos, resulta na depredação do meio ambiente e na exploração do trabalho e dos trabalhadores marcados neste processo com o signo do adoecimento e não raramente da morte.

Focou-se especificamente, na condição de vida e trabalho dos trabalhadores-migrantes nordestinos, apontando os indiscutíveis efeitos maléficos da atividade de cortar cana-de-açúcar sobre os corpos e mentes dos trabalhadores inseridos nesse processo, sendo que, ao destacar a 
figura dos trabalhadores-migrantes tais efeitos ganham novos contornos, visto que a experiência do adoecimento tende a ser vivida no interior de outro evento traumático representado pela distância com relação aos seus familiares.

Os dados apresentados ao longo do artigo permitem perceber a perversidade de um desenvolvimento entendido unicamente numa perspectiva econômica.

Nessa perspectiva e sob a lógica do capital, o desenvolvimento, mesmo em sua vertente sustentável, não passa de um engodo, ideia esta defendida por Ramos ${ }^{35}$, citado por Freitas et al. ${ }^{36}$, para quem, "sob o ponto de vista das relações de produção capitalista é impossível qualquer modalidade de desenvolvimento sustentável, com vigência ampla e duradoura e que venha salvaguardar os recursos naturais e humanos do planeta Terra".

Para Leff ${ }^{37}$, citado por Freitas et. al. ${ }^{36}$, "a sustentabilidade ambiental está diretamente relacionada à satisfação das necessidades básicas das populações", processo este fortemente dependente "de uma estratégia de desenvolvimento sustentável, capaz de promover atividades produtivas que permitam um aproveitamento ecologicamente racional dos recursos naturais, reduzindo os custos ecológicos".

No caso brasileiro, tal processo demanda um novo pacto em torno de um novo modelo de agricultura, cujo centro seja a gestão sustentável dos recursos ecológicos e a garantia da qualidade dos produtos agrícolas e dos processos de sua produção, a busca da soberania alimentar etc. ${ }^{22}$.

Como lembra Wanderley ${ }^{21}$, nossas sociedades estão cada vez mais desacreditadas de um modelo de desenvolvimento que se apresenta socialmente excludente e ambientalmente nocivo ao planeta e ao conjunto dos seres vivos. Nesse sentido faz-se necessário aprofundar o debate e a luta em torno de outro mundo possível, estendendo, ou melhor, transferindo o voto de confiança outrora depositado no grande latifúndio para os camponeses, entendidos não como atores pretéritos, mas como atores que cuidam do ser vivo, plantas e animais. Diretamente, quase individualmente, afetivamente ${ }^{38}$. Ainda citando Wanderley ${ }^{21}$

$E$ É interessante perceber como, neste contexto, o conceito de camponês volta à cena. Ele se refere a um ator social, profundamente enraizado em seu território de vida e de trabalho e, enquanto tal conhecedor das exigências que a natureza impõe ao trato dos seres vivos. É com esta "bagagem", que ele pode se colocar, modernamente, como mediador entre o campo e a cidade, a produção e o consumo, comprometendo-se, junto à população urbana com a qualidade do que produz.

Para tanto se torna necessário retomar a questão em torno da questão agrária e da necessária reforma agrária que não passe apenas e exclusivamente pelo acesso a terra (e terras inférteis), mas pelo acesso a condições de vida e de trabalho no campo, que atenda aos padrões de dignidade socialmente aceitos.

Reconhecendo que o campo não é sinônimo apenas de agricultura, faz-se necessário investir no dinamismo das regiões rurais promovendo o acesso da população que ai vive a outras formas de trabalho e renda (a exemplo do turismo rural).

Por fim, é importante ampliar a oferta da educação do campo, com qualidade, como forma de capacitar os jovens para que tanto a saída quanto a permanência no campo deixe de ser um destino e passe a ser fruto de uma opção consciente.

O desafio essencial passa, portanto, pela construção de políticas públicas inovadoras para o meio rural brasileiro e para os jovens que aí vivem; políticas que deem acesso ao trabalho, renda, educação e outros serviços básicos, inclusive, já garantidos na legislação brasileira. Mas, para isto, um novo modelo de nação e de desenvolvimento rural faz-se necessário. E como canta a cirandeira de Itamaracá: Esta ciranda não é minha só, ela é de todos nós, ela é de todos nós.

\section{Colaboradores}

Costa PFF, Silva MS, Santos SL participaram igualmente de todas as etapas de elaboração do artigo. 


\section{Referências}

1. Dana S. A importância da agricultura brasileira em números. [acessado 2014 abr 25]. Disponível em: http://www1.folha.uol.com.br/colunas/carodinheiro/2014/03/1425887-a-importancia-da-agricultura -brasileira-em-numeros.shtml

2. Nuvens de veneno (documentário). Direção de Roberto Novaes. $23 \mathrm{~min}$. Rio de Janeiro: Terra Firme, MP2 Produções, Videosaúde distribuidora; 2013.

3. Furtado C. O mito do desenvolvimento econômico. Rio de Janeiro: Paz e Terra; 1974.

4. Cavalcanti C. Meio ambiente, Celso Furtado e o desenvolvimento como falácia. In: Lima MC, David MD, organizadores. A atualidade do pensamento de Celso Furtado. São Paulo: Francis; 2008. p. 199-214.

5. Cervo AL, Bervian PA. Metodologia científica: para uso dos estudantes universitários. São Paulo: McGraw-Hill do Brasil; 1983.

6. Gonçalves DB. Considerações sobre a expansão recente da lavoura canavieira no Brasil. Rev. Informações econômicas 2009; 39(10):70-82.

7. Ioris AAR. Segurança alimentar e segurança energética: algumas questões de ecologia política. Cadernos do desenvolvimento 2013; 6(8):355-374.

8. Ziegler JZ. Folha de S. Paulo, Caderno Mais. $2007 \mathrm{dez}$ 2. p. 6-7.

9. Kohlhepp G. Análise da situação da produção do etanol e biodiesel no Brasil. Estudos Avançados 2010; 24(68):223-253.

10. Abramovay R. Avanços recentes e ameaças à segurança alimentar mundial. In: Anais do Seminário Nacional Mesa Brasil SESC: segurança alimentar e nutricional: desafios e estratégias; 2010; Rio de Janeiro. p. 88-97.

11. Rigotto RM, Carneiro FF, Marinho AMCP, Rocha MM, Ferreira MJM, Pessoa VM, Teixeira ACA, Silva MLV, Braga LQV, Teixeira MM. O verde da economia no campo: desafios à pesquisa e às políticas públicas para a promoção da saúde no avanço da modernização agrícola. Cien Saude Colet 2012; 17(6):1533-1542.

12. Szmrecsanyi T, Gonçalves DB. Efeitos socioeconômicos e ambientais da expansão da lavoura canavieira no Brasil. [acessado 201422 abr] Disponível em: http:// lasa.international.pitt.edu/members/congresspapers/ lasa2009/files/SzmrecsanyiTamas.pdf

13. Silva MS. Trabalhadores Migrantes nos canaviais paulistas: sociabilidades, trabalho e formas de resistência [tese]. Campina Grande: Universidade Federal de Campina Grande; 2011.

14. Costa PFF, Silva MS. Migração, sofrimento psíquico e estratégias defensivas "dos que migram" e "dos que ficam”. Rev. Saúde Coletiva em Debate 2011; 1(1):15-30.

15. Menezes MA. Juventude Rural do Nordeste: Trabalho, Migração e Movimentos Sociais. Campina Grande: CNPq, UFCG; 2009. (mimeo). (Relatório Acadêmico Sintético)

16. Foucault M. Vigiar e punir: nascimento da prisão. Petrópolis: Vozes; 2008.

17. Alves F. Migração de trabalhadores rurais do Maranhão e Piauí para o corte de cana em São Paulo. In: Novaes JR, Alves F, organizadores. Migrantes: Trabalho e trabalhadores no Complexo Agroindustrial canavieiro (os heróis do agronegócio brasileiro). São Carlos: Ed. UFSCAR; 2007. p. 21-54.
18. Silva MAM. Trabalho e trabalhadores na região do "mar de cana e do rio de álcool". In: Novaes JR, Alves F, organizadores. Migrantes: trabalho e trabalhadores no complexo agroindustrial canavieiro (os heróis do agronegócio brasileiro). São Carlos: Ed. UFSCAR; 2007. p. 55-86.

19. Silva MAM, Ribeiro JD. Violação dos Direitos e formas de resistência nos canaviais paulistas. In: VIII Congresso da ALASRU; 2010; Recife. Disponível em: http://www. alasru.org/wp-content/uploads/2011/09/GT21-MARIA-APARECIDA-DE-MORAES-SILVA.pdf

20. Carlos MG. Produção de conhecimento e intersetorialidade em prol das condições de vida e de saúde dos trabalhadores do setor sucroalcooleiro. Cien Saude Colet 2011; 16(8):3361-3368.

21. Wanderley MNB. A sociologia rural na América Latina: produção de conhecimento e compromisso com a sociedade. ALASRU Nueva Época 2010; 5:17-44.

22. Silva MAM. Do Karoshi no Japão à birola no Brasil. Revista Nera 2006; 9(8):74-108.

23. Rocha FL. A análise dos fatores de risco do corte manual e mecanizado da cana-de-açúcar no Brasil segundo referencial da Promoção da Saúde [tese]. Ribeirão Preto: Universidade de São Paulo; 2007.

24. Alves F. Porque morrem os cortadores de cana? Revista Saúde e Sociedade 2006; 15(3):90-98.

25. Alessi NP, Scopinho RA. A saúde do trabalhador do corte da cana de açúcar. In: Alessi NP, Palocci Filho A, Pinheiro SA, Scopinho RA, Silva GB, organizadores. Saúde e trabalho no Sistema Único de Saúde. São Paulo: Hucitec; 1994. p. 121-155.

26. Ramos P. O trabalho na lavoura canavieira paulista: evolução recente, situação atual e perspectiva. In: Buainain AM, Deddeca CS, coordenadores. Emprego e trabalho na agricultura brasileira. Brasília: IICA; 2008. p. 306-327.

27. Guanais JB. No eito da cana, a quadra é fechada: estratégias de dominação e resistência entre patrões e cortadores de cana em Cosmópolis/SP [dissertação]. Campinas; Instituto de Filosofia e Ciências Humanas; 2010.

28. União da Agroindústria Canavieira de São Paulo (Unica). Projetos e Iniciativas [internet]. 2013. [acessado 2014 fev 05]. Disponível em: http://www.unica.com. br/protocolo-agroambiental/

29. Menezes MA, Silva MS, Cover M. Os impactos da mecanização da colheita de cana-de-açúcar sobre os trabalhadores migrantes. Ideias 2011; 2(1):59-87.

30. Baccarin JG, Gebara JJ. Intensificação do Ritmo e Redução de Postos de Trabalho dos Trabalhadores Canavieiros no Estado de São Paulo, Brasil. Disponível em: www. fcav.unesp.br/baccarin/Artigo\%2012\%20ALAST.doc

31. Alves F. Políticas Públicas compensatórias para a mecanização do corte de cana crua: indo direto ao ponto. RURIS 2009; 3(1):153-178.

32. Cardoso FH. Incentivo do Estado do desenvolvimento: uma análise sobre o crescimento da área da construção civil. In: Semana de Ciências Sociais: Departamento de Ciências Sociais, Universidade Estadual de Londrina; 2013. [acessado 2014 fev 6]. Disponível em: http:// www.uel.br/eventos/semanacsoc/pages/arquivos/GT\% 208/Cardoso\%20Fernando\%20Henrique\%20-\%20 Artigo.pdf 
33. Rocha R, Hashizume M. Construção civil combina recordes de empregos e problemas. Repórter Brasil, 2010. [acessado 201409 mai]. Disponível em: http://reporterbrasil.org.br/2010/10/construcao-civil-combina-recorde-de-empregos-e-problemas/

34. Sen A. Desenvolvimento como liberdade. São Paulo: Companhia das Letras; 2010.

35. Ramos MHR. Desenvolvimento sustentável numa perspectiva crítica. 2010. [acessado 2014 abr 28]. Disponível em: http://www.redecomunaverde.org/rede/index. php?option $=$ com_content\&view $=$ article\&id $=68$ : dese

36. Freitas RCM, Nélsis CM, Nunes LS. A crítica marxista ao desenvolvimento (in) sustentável. Rev. katálysis 2012; 15(1):41-51.

37. Leff E. Ecología y capital: racionalidad ambiental, democracia participativa y desarrollosustentable. México, Buenos Aires: Siglo Veintiuno Editores; 1994.

38. Brandão CR. O afeto da terra: imaginários, sensibilidades e motivações de relacionamentos com a natureza e $o$ meio ambiente entre agricultores e criadores sitiantes do Bairro dos Pretos, nas encostas paulistas da Serra da Mantiqueira, em Joanópolis. Campinas: Editora da Unicamp; 1999.

Artigo apresentado em 07/07/2014

Aprovado em 11/07/2014

Versão final apresentada em 12/07/2014 